\section{A Simple Model for Rapid and Nondestructive Estimation of Bell Pepper Fruit Volume}

\author{
Mathieu Ngouajio ${ }^{1}$ \\ Department of Horticulture, Michigan State University, East Lansing, \\ MI 48824-1325
}

William Kirk

Department of Plant Pathology, Michigan State University, East Lansing, MI 48824-1325

\author{
Ronald Goldy \\ Southwest Michigan Research and Extension Center, Michigan State University, \\ 1791 Hillandale Road, Benton Harbor, MI 49022
}

Additional index words. Capsicum annuum, fruit shape, yield prediction, equation, water displacement

\begin{abstract}
Nondestructive estimates of fruit volume are used for yield prediction. They are also used to study the relationship between fruit expansion rate and susceptibility to diseases or physiological disorders such as fruit cracking. A model relating bell pepper (Capsicum annuum) fruit diameter and length to its volume was derived using the equation of the volume of a sphere as the starting point. The model has the following formula: $V_{F}=K D^{2} L \pi / 6$, where $V_{F}$ is fruit volume, $K$ is the shape factor that varies with fruit type, $D$ is fruit diameter, and $L$ is fruit length. The model is simple, easy to use in the field, and may account for variations in fruit shape. Regression analyses using actual fruit volume of bell pepper measured with the water displacement method and the volume estimated using different equations showed that accuracy of the new model is comparable to that of one of the best models previously proposed. However, because the model is less complex than previous models, it is easier to use in the field.
\end{abstract}

Nondestructive measurements of fruit size are used to develop models for final yield predictions (Jenni et al., 1997, 1998; Mitchell, 1986; Williams et al., 1969). These models are routinely used in tree fruit production (Mitchell, 1986). The ability to measure fruit size without harvesting the fruit allows for monitoring individual fruit growth over time, and to develop fruit growth curves (Jenni et al., 1997; Mitchell, 1986). Fruit growth curves may have several applications, including yield prediction at harvest (Jenni et al., 1998; Russo, 1996). These curves may also be used to study the effects of fruit expansion rate on their susceptibility to diseases and physiological defects, such as fruit cracking (Milad and Shackel, 1992). Prediction accuracy is, therefore, closely related to accuracy of the fruit size estimation tool used (Jenni et al., 1997).

Several approaches have been proposed to estimate fruit volume (Assaf et al., 1982; Caspari et al., 1993; Chalmers et al., 1981; Currence et al., 1944; Russo, 1996). The simplest

Received for publication $28 \mathrm{Feb}$. 2002. Accepted for publication 17 Oct. 2002. We thank Korsi Dumenyo and Jinsheng Huang for their critical comments on the early version of this work. This research was supported by Michigan State Univ. Agricultural Experiment Station.

${ }^{1}$ To whom reprint requests should be sent. Telephone: (517) 432-2241; Fax: (517) 432-2242; E-mail address: ngouajio@msu.edu approach has been to assume that fruits are spherical and use diameter or circumference to calculate volume (Caspari et al., 1993; Chalmers et al., 1981). Although this method provides adequate estimation of volume for some fruits, it does not work for fruits with irregular shapes, such as peppers (Caspari et al., 1993; Mitchell, 1986; Russo, 1996). Russo (1996) used the formula for a cone to estimate bell pepper (Capsicum annuum) fruit volume. The equation $\mathrm{Y}=\mathrm{aX} \mathrm{X}^{\mathrm{b}}(\mathrm{X}$ being the circumference) was proposed as an alternative method to measure fruit volume (Assaf et al., 1982). This equation improved estimates of pear volume compared with estimates using sphere volume (Mitchell, 1986). However, equation accuracy is not highly improved since it uses one variable, just like the equation of the sphere, the major difference being just the logarithmic transformation. Using this equation, fruit shape will still affect accuracy of the estimates. A more accurate estimate of fruit volume should encompass variation in fruit shape. Such a model would require at least two variables. The model proposed by Currence et al. (1944) meets this requirement. The model has the following formula:

$$
\mathrm{Y}=\mathrm{KD}^{2} \mathrm{~L} / 1000
$$

where:

$$
\begin{aligned}
& K=0.1528(D / L)+0.4152, \text { if }(D / L) \leq 1 ; \\
& K=-0.2204(D / L)+0.7872 \text {, if }(D / L)>1 ;
\end{aligned}
$$

and $\mathrm{Y}$ is fruit volume $\left(\mathrm{cm}^{3}\right) ; \mathrm{K}$ is a shape factor; $\mathrm{D}$ is fruit diameter $(\mathrm{mm})$; and $\mathrm{L}$ is fruit length $(\mathrm{mm})$. This equation was shown to provide accurate estimates of muskmelon (Cucumis melo) ovary volume (Jenni et al., 1997, 1998). The equation was specifically developed to estimate muskmelon fruit volume, and has not been tested on many fruits with different shapes. Major limitations of the equation proposed by Currence et al. (1944) reside in the fact that: 1) the model is complex due to the K component; and 2) the use of two values for $\mathrm{K}$ depending on the $\mathrm{D} / \mathrm{L}$ ratio, makes the equation inappropriate for rapid estimation of fruit volume. A model with the accuracy of the model of Currence et al. (1944), but with a unique and constant value of $\mathrm{K}$ would allow quicker estimation of fruit volume in the field.

Objectives of this work were: 1) to derive from the equation of the volume of a sphere, a simple and accurate model relating nondestructive fruit measurements to fruit volume; and 2) to validate the model using data on bell pepper fruits of contrasting shapes.

\section{Materials and Methods}

Model derivation. Nondestructive estimation of fruit volume is routinely conducted using diameter and circumference measurements, and by assuming that the fruit is spherical (Batjer et al., 1957; Chalmers et al., 1981; Mitchell, 1986). The volume of a sphere is given by the following formula:

$$
\mathrm{V}_{\mathrm{S}}=\mathrm{D}^{3} \pi / 6
$$

where $V_{S}$ is the sphere volume and $D$ is its diameter. If a fruit is perfectly spherical, its diameter (D) and its length (L) will be equal. However, fruits are rarely perfect spheres. Most fruits are either flat $(D>L)$ or long $(D<L)$. Flat fruits and long fruits are overestimated or underestimated, respectively by Eq. 1. A simple way to account for variation in fruit shape is to use the ratio $(\mathrm{R})$ of length to diameter: $\mathrm{R}$ $=\mathrm{L} / \mathrm{D}$. When $\mathrm{R}$ equals one, fruit volume is estimated adequately with Eq. 1 . When $\mathrm{R}$ is smaller or greater than one, volume is overor underestimated, respectively. Amount of deviation from $\mathrm{R}=1$ can be calculated and subtracted or added to the initial volume estimate. Corrected fruit volume will, therefore, have the following equation:

$$
\mathrm{V}_{\mathrm{F}}=\mathrm{V}_{\mathrm{S}}+\mathrm{V}_{\mathrm{S}}(\mathrm{KR}-1)
$$

where $\mathrm{V}_{\mathrm{F}}$ is the corrected fruit volume, and $\mathrm{K}$ is a shape factor that varies with fruit type. After development and rearrangement of Eq. 2 , the following equation is obtained:

$$
\mathrm{V}_{\mathrm{F}}=\mathrm{KD}^{2} \mathrm{~L} \pi / 6
$$

The value of $\mathrm{K}$ can be determined by iteration, with the objective of minimizing the residual mean squares of the regression. The calculated value of $\mathrm{K}$ for peppers the fruits used in this work was 1.1. With this value, Eq. 3 becomes:

$$
\mathrm{V}_{\mathrm{F}}=1.1 \mathrm{D}^{2} \mathrm{~L} \pi / 6
$$

with $\mathrm{D}$ and $\mathrm{L}$ in $\mathrm{cm}$ and $\mathrm{V}_{\mathrm{F}}$ in $\mathrm{cm}^{3}$. 
Model validation. The proposed model (Eq. 4) for nondestructive estimation of fruit volume was validated using data from field experiments conducted in 2001 on 19 bell pepper cultivars. Peppers were selected for this validation because of the large diversity in size and shape among different cultivars. Table 1 lists the shapes of the fruits from the cultivars. The trial was located at Michigan State Univ., Southwest Michigan Research and Extension Center, Benton Harbor. Peppers were produced using black plastic mulch and drip irrigation. At harvest, 10 fruits per cultivar were used (190 fruits total). Preliminary studies showed low variability in fruit shape within individual cultivars, therefore reducing the need for a larger sample size per cultivar. Diameter and length of each fruit were measured using a digital caliper. Fruit length was measured from blossom end to the top of the shoulder and the diameter was measured at the fruit shoulder (Russo, 1996). Actual fruit volume was measured using the water displacement technique as a standard against which model estimates were compared (Jenni et al., 1997; Milad and Shackel, 1992;

Table 1. Diameter (D), length (L), L/D ratio, and shape of the bell pepper fruits used in the experiment.

\begin{tabular}{|c|c|c|c|c|}
\hline $\begin{array}{l}\text { Pepper } \\
\text { cultivar }\end{array}$ & $\begin{array}{l}\text { Diameter } \\
(\mathrm{mm})\end{array}$ & $\begin{array}{l}\text { Length } \\
(\mathrm{mm})\end{array}$ & $\mathrm{L} / \mathrm{D}$ ratio & Shape $^{z}$ \\
\hline E 41.5463 & $96.2(6.5)^{y}$ & 92.1 (7.7) & $0.96(0.11)$ & Round \\
\hline Orion & $98.7(3.1)$ & $84.2(4.1)$ & $0.85(0.06)$ & Flat \\
\hline Legionnaire & 90.9 (2.9) & $95.1(8.3)$ & $1.05(0.10)$ & Round \\
\hline Crusader & $97.9(5.8)$ & $87.4(3.1)$ & $0.90(0.07)$ & Flat \\
\hline Maxi-bell & $88.3(5.8)$ & $80.5(10.1)$ & $0.92(0.16)$ & Flat \\
\hline Yellow-bell & $83.1(6.8)$ & $77.2(8.5)$ & $0.94(0.15)$ & Flat \\
\hline Vivaldi & 94.7 (3.9) & $114.3(18.4)$ & $1.21(0.20)$ & Long \\
\hline SPP 7117 & 91.5 (6.4) & $88.6(4.5)$ & $0.97(0.09)$ & Round \\
\hline SPP 8124 & $94.6(6.8)$ & 94.1 (11.7) & $1.00(0.18)$ & Round \\
\hline SPP 8125 & $88.3(3.5)$ & $91.5(6.3)$ & $1.04(0.10)$ & Round \\
\hline ACX 209 & 95.7 (5.6) & $94.8(10.0)$ & $1.00(0.14)$ & Round \\
\hline ACX 220 & $90.6(6.1)$ & $102.2(13.5)$ & $1.13(0.13)$ & Long \\
\hline ACX 228 & $94.0(7.4)$ & $103.3(8.1)$ & $1.11(0.16)$ & Long \\
\hline 830 & $93.4(8.1)$ & 92.3 (11.9) & $0.99(0.11)$ & Round \\
\hline HA 510 & $84.1(4.0)$ & $122.2(7.9)$ & $1.45(0.11)$ & Long \\
\hline HA 744 & $92.4(5.1)$ & $76.0(5.5)$ & $0.82(0.07)$ & Flat \\
\hline HA 769 & $91.5(9.2)$ & $87.2(6.8)$ & $0.97(0.16)$ & Round \\
\hline HA 959 & $85.6(6.3)$ & $76.2(10.5)$ & $0.90(0.16)$ & Flat \\
\hline HA 1038 & 86.7 (6.4) & 111.7 (13.9) & $1.30(0.23)$ & Long \\
\hline$P$ value $^{\mathrm{x}}$ & 0.0001 & 0.0001 & 0.0001 & --- \\
\hline
\end{tabular}

${ }^{2} \mathrm{~A}$ fruit was classified as (1) Round when the ratio of length to diameter was between 0.95 and 1.05 ; (2) Flat when the L/D was $<0.95$; and (3) Long when L/D was $>1.05$.

${ }^{y}$ Numbers in parentheses are standard deviations of the means.

${ }^{x} P$ values indicate the level of significance.
Mitchell, 1986). Estimated volumes were calculated using: 1) fruit diameter in Eq. 1;2) fruit length and diameter measurements in Currence et al. (1944) equation; and 3) fruit length and diameter measurements in Eq. 4.

Statistical analysis. Simple linear regression analyses of measured and estimated fruit volumes were conducted. All analyses were preformed using SAS (SAS Institute, Cary, NC, 1989).

\section{Results and Discussion}

The model derived from the equation for the volume of a sphere is simple to use. It uses both fruit diameter and fruit length as input variables and the value of the shape coefficient (K) can be considered equal to one. However, accuracy can be improved by calculating the exact value of $\mathrm{K}$ for a given fruit type. In such situations, a small sample of fruits can be used to calculate K. For this purpose, the regression is performed using $\mathrm{K}=1 \mathrm{first}$, and thereafter, increasing or decreasing its value until the residual mean squares is minimum. Using this technique, the value of $\mathrm{K}$ for bell peppers was determined to be 1.1 .

The fruits used had large shape differences. Using length over diameter (L/D) ratio, fruit shape was described for each cultivar (Table 1). Five cultivars had long fruits, 6 had flat fruits, and 8 had fruits closer to the shape of a sphere. Using fruits of contrasting shapes was key to validating the model. When the equation of the volume of a sphere was used, large deviations were observed in estimated fruit volume (Table 2). Analyses of variance using data on the deviations from the actual values of volume (measured with the water displacement method) showed highly significant differences among pepper cultivars $(P<$ $0.0001)$. This observation confirms previous

Table 2. Peppers fruit volume measured using the water displacement method (measured volume), the equation of the volume of a sphere (Eq. 1), the equation of Currence et al. (1944), and the new equation (Eq. 4).

\begin{tabular}{|c|c|c|c|c|c|c|c|}
\hline \multirow{3}{*}{$\begin{array}{l}\text { Pepper } \\
\text { cultivar }\end{array}$} & \multirow{3}{*}{$\begin{array}{l}\text { Measured volume } \\
\text { mean }\left(\mathrm{cm}^{3}\right)\end{array}$} & \multicolumn{6}{|c|}{ Estimated volume and method of estimation } \\
\hline & & \multicolumn{2}{|c|}{ Sphere's equation } & \multicolumn{2}{|c|}{ Currence's equation } & \multicolumn{2}{|c|}{ New equation } \\
\hline & & $\overline{\text { Mean }\left(\mathrm{cm}^{3}\right)}$ & $\operatorname{Deviation}^{2}(\%)$ & Mean $\left(\mathrm{cm}^{3}\right)$ & $\operatorname{Deviation}^{2}(\%)$ & Mean $\left(\mathrm{cm}^{3}\right)$ & $\operatorname{Deviation}^{2}(\%)$ \\
\hline$\overline{\mathrm{E} 41.5463}$ & 513 & 472 & -8.0 & 468 & -8.8 & 493 & -3.9 \\
\hline Orion & 516 & 504 & -2.3 & 432 & -16.3 & 471 & -8.7 \\
\hline Legionnaire & 464 & 394 & -15.1 & 433 & -6.7 & 452 & -2.6 \\
\hline Crusader & 464 & 495 & 6.7 & 451 & -2.8 & 483 & 4.1 \\
\hline Maxi-bell & 335 & 364 & 8.7 & 331 & -1.2 & 359 & 7.2 \\
\hline Yellow-bell & 308 & 306 & -0.6 & 285 & -7.5 & 307 & -0.3 \\
\hline Vivaldi & 549 & 449 & -18.2 & 553 & 0.7 & 594 & 8.2 \\
\hline SPP 7117 & 422 & 405 & -4.0 & 408 & -3.3 & 427 & 1.2 \\
\hline SPP 8124 & 472 & 448 & -5.1 & 455 & -3.6 & 482 & 2.1 \\
\hline SPP 8125 & 418 & 361 & -13.6 & 394 & -5.7 & 410 & -1.9 \\
\hline ACX 209 & 481 & 463 & -3.7 & 472 & -1.9 & 499 & 3.7 \\
\hline ACX 220 & 451 & 394 & -12.6 & 462 & 2.4 & 488 & 8.2 \\
\hline ACX 228 & 534 & 442 & -17.2 & 503 & -5.8 & 525 & -1.7 \\
\hline 830 & 511 & 435 & -14.9 & 450 & -11.9 & 472 & -7.6 \\
\hline HA 510 & 457 & 313 & -31.5 & 451 & -1.3 & 499 & 9.2 \\
\hline HA 744 & 341 & 416 & 22.0 & 337 & -1.2 & 375 & 9.9 \\
\hline HA 769 & 451 & 411 & -8.9 & 397 & -12.0 & 422 & -6.4 \\
\hline HA 959 & 344 & 333 & -3.2 & 295 & -14.2 & 321 & -6.7 \\
\hline HA 1038 & 484 & 346 & -28.5 & 448 & -7.4 & 482 & -0.4 \\
\hline Mean & 448 & 408 & -8.9 & 422 & -5.8 & 451 & 0.7 \\
\hline$P$ value & 0.0001 & 0.0001 & 0.0001 & 0.0001 & 0.0774 & 0.0001 & 0.0653 \\
\hline
\end{tabular}

${ }^{2}$ The deviation was calculated as the difference (\%) between the actual and the estimated volume. Positive values indicate that fruit volume is overestimated and negative values indicate that fruit volume is underestimated.

${ }^{y} P$ values indicate the level of significance. 
reports that the assumption of spherical fruits in volume estimation is erroneous (Caspari et al., 1993; Mitchell, 1986). Both the equation proposed by Currence et al. (1944) and the new equation improved accuracy of fruit volume estimates (Table 2). Deviations from actual values obtained with the two equations were comparable and nonsignificant among the 19 pepper cultivars used. This is an indication that the two equations adequately account for variation in fruit shape.

When the regression of estimated over measured fruit volume was performed using individual fruits, values of the coefficient of determination $\left(r^{2}\right)$ were $0.24,0.66$, and 0.65 for the equation of the volume of a sphere, Currence's equation, and the new equation, respectively (Fig. 1). Similar results were found when regressions were performed using the mean volume for each cultivar (data not shown). The $r^{2}$ values were $0.41,0.88$, and 0.86 for the equation of the volume of a sphere, Currence's equation, and the new equation, respectively. These results once again confirmed the inaccuracy of estimates from the equation of the volume of a sphere. All equations had

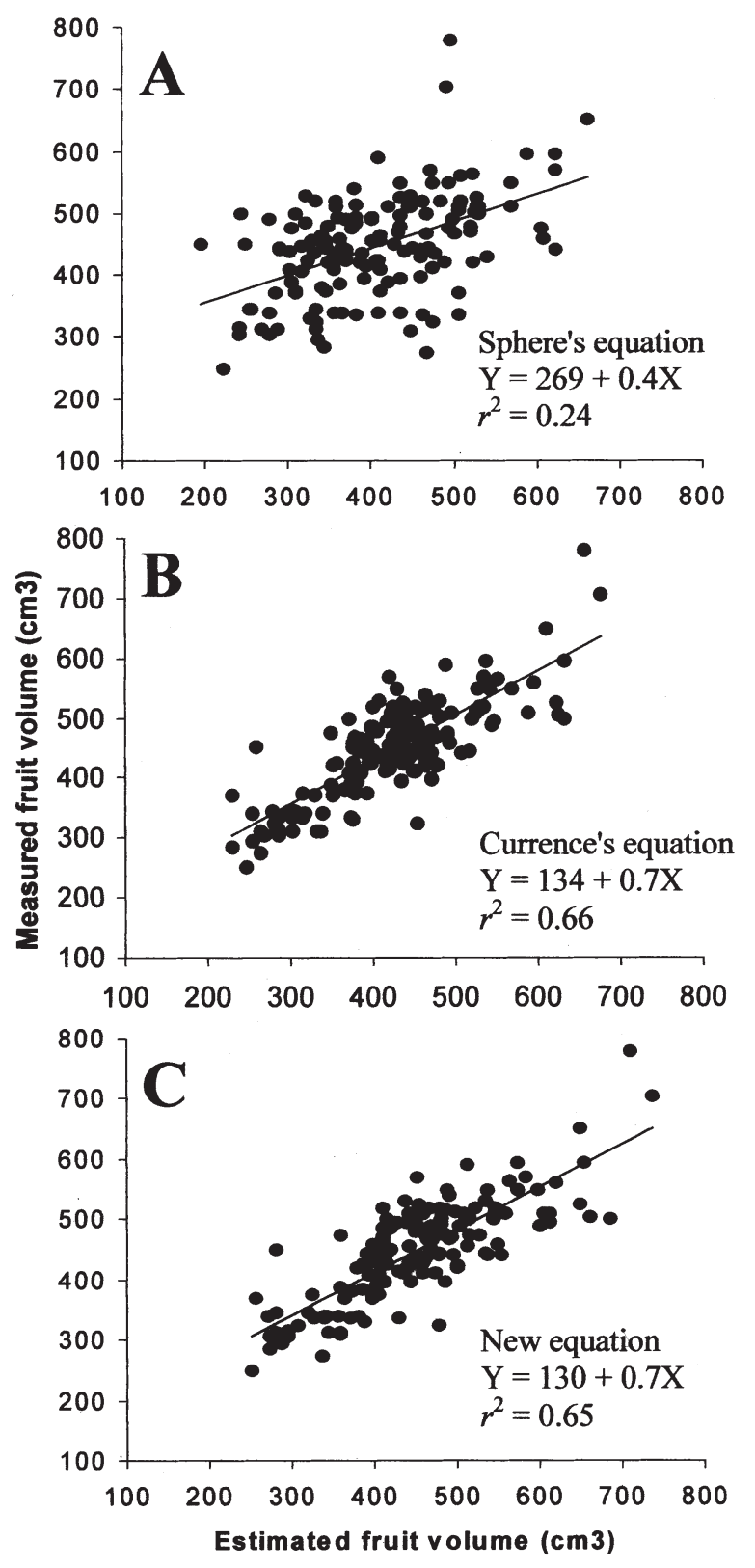

Fig. 1. Relationship between peppers fruit volume measured by water displacement and volume estimated using either (A) fruit diameter in the sphere equation or $(\mathbf{B})$ fruit diameter and length in the equation of Currence et al. (1944), or (C) fruit diameter and length in the improved equation (Eq. 4). Each data point represents individual fruits. There are 19 different pepper cultivars with 10 fruits per cultivar. a Y-intercept $>0$ and a slope $<1$, indicating that actual fruit volume was underestimated for both small and large size fruits. Additional corrections may be performed to get prediction values closer to the measured values.

The equation proposed by Currence et al. (1944) and the new equation had comparable predictive values. The two models accounted for variations in peppers fruit shape, and can therefore be used for nondestructive estimation of fruit volume. However, the new model is less complex and may be easier to use than Currence's model. Currence's model uses a complex term for $\mathrm{K}$, and $\mathrm{K}$ has two values, with the correct value being dictated by the shape of the fruit $(\mathrm{D} / \mathrm{L})$. This may involve an extra step to determine the ratio of diameter over length when fruit shape is not obvious. The new model has a unique $\mathrm{K}$ factor, with a value close to one in most cases. This model may therefore allow a rapid, nondestructive, and accurate estimation of the volume of many fruit types in the field.

\section{Literature Cited}

Assaf, R., I. Levin, and B. Bravdo. 1982. Apple fruit growth as a measure of irrigation control. HortScience 17:59-61.

Batjer, L.P., H.A. Billingsley, M.N. Westwood, and B.L. Rogers. 1957. Predicting harvest size of apples at different times during the growing season. Proc. Amer. Soc. Hort. Sci. 70:46-57.

Caspari,H.W., M.H. Behboudian, D.J.Chalmers, and A.R. Renquist. 1993. Pattern of seasonal water use of Asian pears determined by lysimeters and heat-pulses technique. J. Amer. Soc. Hort. Soc. 118:562-569.

Currence, T.M., R.E. Lawson, and R.M. Brown. 1944. A rapid method for finding the volume and density of muskmelon fruits. J. Agr. Res. 68:427-440.

Chalmers, D J., P.D. Mitchell, and L. van Heek. 1981. Control of peach tree growth and productivity by regulated water supply, tree density, and summer pruning. Proc. Amer. Soc. Hort. Sci. 106:307-312.

Jenni, S., K.A. Stewart, G. Bourgeois, and D.C. Cloutier. 1997. Nondestructive volume estimation for growth analysis of eastern-type muskmelon ovaries. HortScience 32:342-343.

Jenni, S., K.A. Stewart, G. Bourgeois, and D.C. Cloutier. 1998. Predicting yield and time to maturity of muskmelons from weather and crop observations. J. Amer. Soc. Hort. Sci. 123:195-201.

Milad, E.E. and K.A. Shackel. 1992. Water relations of fruit end cracking in French prune (Prunus domestica L. cv. French). J. Amer. Soc. Hort. Sci. 117:824-828.

Mitchell, P.D. 1986. Pear fruit growth and the use of diameter to estimate fruit volume and weight. HortScience 21:1003-1005.

Russo, W.M. 1996. Delaying harvest improves bell pepper yield. HortScience. 31:345-346.

SAS Institute, Inc.. 1989. SAS/STAT user's guide, vol. 2, version 6, 4th ed. SAS Inst., Cary, N.C.

Williams, M.W., H.D. Billingsley, and L.P. Batjer. 1969. Early season harvest size prediction of Bartlett pear. J. Amer. Soc. Hort. Sci. 94: 596-598. 